\title{
ESTUDOS HUSSERLIANOS \\ DE MARIA MANUELA SARAIVA
}

\author{
Joaquim Carlos Araújo \\ Escola Secundária José Afonso - Loures
}

\section{Nota prévia}

É nosso intuito mostrar a originalidade do pensamento fenomenológico da professora da Universidade de Lisboa, Maria Manuela Saraiva, qual o seu pontual contributo para o panorama filosófico português e quais as suas teses fundamentais acerca da fenomenologia husserliana, dentro dos textos por si estudados. Focaremos a nossa atenção especialmente nos textos husserlianos, chamemos-lhe assim, da autora, a saber,

i) 1963-L'imagination selon Husserl - tese de doutoramento defendida, neste ano, na Universidade de Lovaina, publicada na coleção "Phaenomenologica" (Haia: M. Nijhoff) em 1970 e traduzida para português em 1994;

ii) $1964-« O$ primado da perceção e a conceção da obra de arte em Husserl» - conferência proferida num histórico colóquio em Braga, que permitiu fundar o Centro de Estudos Fenomenológicos na mesma cidade;

iii) 1965 - Prefácio a $A$ obra de arte literária, de Roman Ingarden, publicada pela Fundação Calouste Gulbenkian.

Por outro lado, e devemos desde já anunciá-lo, não caberá aqui explicitar até que ponto a filosofia de Sartre terá influenciado a nossa autora. Procuraremos, isso sim, concluir, eventualmente, acerca de uma (ou várias) tendência(s) ou Leitmotiv filosófico que inspirou a professora a dedicar parte da sua reflexão a um assunto ainda hoje tão pouco explorado e mal compreen- 
dido pelo público português leitor-de-filosofia. Na verdade, passaram 30 anos depois da filósofa ter escrito, no seu Prefácio a «A obra de arte literária», o seguinte: «Mas, num país onde o pensamento husserliano é tão mal conhecido, esta tradução pode constituir um perigo grave: o de atribuir a Ingarden ideias que são de Husserl ou de pôr em circulação como husserlianas ideias e teorias que, de facto, o não são». Ora, esta necessidade de defender uma certa digamos assim pureza husserliana no pensamento seu contemporâneo, nacional e internacional, poderá ter veementemente alimentado o interesse reflexivo de Maria Manuela Saraiva que, com grande probabilidade, e com toda a justeza no nosso ponto de vista, terá descoberto em Husserl, há já mais de 60 anos na nossa universidade, e para além das interpretações mais formais ou mais interessadas, a grande novidade filosófica do século XX.

\section{PARTe I}

\section{Imaginação versus consciência estética em Husserl}

\section{Introdução}

L'imagination selon Husserl, ${ }^{1}$ um estudo elaborado durante os anos 50 e editado em 1970, em "Phaenomenologica", coleção sob a responsabilidade dos Centros dos Arquivos-Husserl, posteriormente vertido para a nossa língua, em 1994, consagrou-se como a única grande obra de Maria Manuela Saraiva, dada a sua dimensão temática e conceptual e a sua venerável importância relativamente ao assunto fenomenológico da imaginação, apelando a autores como Fink, Sartre e, praticamente, toda a escola fenomenológica à época conhecida. Já da filosofia feita em Portugal, aí se referem, por exemplo, entre outros, António Morujão, Gustavo de Fraga e Júlio Fragata. O conhecimento dos originais de Husserl, bem como de traduções várias, faz ainda, desta obra, uma incontornável referência no conjunto da produção filosófica no nosso país. Nos quatro capítulos de A Imaginação Segundo Husserl (ISH), relacionam-se, de modo acentuadamente técnico e conhecedor da matéria em análise, os conceitos gerais de intencionalidade, intuição, presentificação e neutralização, aglutinados sobre o eixo central da imaginação.

\footnotetext{
${ }^{1}$ Consultámos o original francês, L'imagination selon Husserl. La Haye: Martinus Nijhoff, 1970 e A Imaginação Segundo Husserl, traduzida do francês por Isabel Támen e António Pedro Mesquita, Paris: Fundação Calouste Gulbenkien, 1994 (Publications du Centre Culturel Calouste Gulbenkien, Paris). Citaremos a versão portuguesa: ISH, seguida da paginação.
} 
A imaginação foi, na verdade, um tema pouco explorado por Husserl, nomeadamente na sua vertente estética, o que faz surgir, logo de início, à autora, um problema de índole deontológica digamos assim: que direito tem um investigador de sistematizar elementos numa obra cujo autor ele próprio não sistematizou? Mais ainda, como fazer a passagem, sem perder o rigor e a perspetiva exógena do historiador, da fenomenologia pré-redutiva das Investigações Lógicas para as Ideias I? Contudo, foi o próprio filósofo que pretendeu melhorar, e não modificar profundamente, a estrutura e o estilo presente em ambas as obras. ${ }^{2}$ Ainda, a dificuldade de isolar uma definição de intencionalidade na obra husserliana, dificultará de sobremaneira a tarefa da professora Maria Manuela Saraiva, se bem que, e apesar disso, o filósofo terá teorizado a essência da intencionalidade enquanto ação constituinte - como o próprio R. Ingarden terá também admitido - de modo a combater a intencionalidade brentaniana que nunca exprimiu, de modo suficiente, o ativo papel da consciência em todo o processo psíquico.

Um dos objectivos específicos de ISH é estudar os elementos da perceção, imaginação, consciência de imagem, recordação e intuição do tempo. Aliás, tais conceitos, por Heidegger considerados como «atos intelectivos inferiores $)^{3}$ ocupam para Maria Manuela Saraiva, um destacado estatuto na obra lógica de Husserl - o que, eventualmente, a expressão de Heidegger o não faria supor.

Resumidamente, duas grandes dificuldades gerais deste estudo:

a) a elucidação do estatuto fenomenológico da imaginação, por parte de Husserl, por confronto direto com outros tipos de consciência, a saber, recordação, perceção, consciência signitiva (ou simbólica) e a função de neutralização da consciência (ou consciência neutra) em geral;

b) a eventual oposição entre a estrutura fenomenológica da imaginação ou presentificação/intuição (o processo base) e as múltiplas distinções que se encontram no interior do próprio fenómeno geral da imaginação (casos particulares).

Mais explicitamente, o termo genérico de imaginação (Bildvorstellung; Imagination) debate-se, em Husserl, com algumas especificações ou particularizações, a saber:

1. a imaginação sensível - conceito tradicional de imaginação. Paralelamente a esta encontramos a discussão acerca da (im)possibilidade da imaginação categorial; 
2. a imaginação propriamente dita - ou a faculdade de produzir imagens mentais e a consciência de imagem (ou consciência de imagem por representação física) - fenómeno desde logo produzido a partir de uma entidade material, por exemplo, fotografia, estátua, pintura, etc. e que nos faz pensar os sujeitos representados por esses objetosimagens. Em suma, foi o próprio Husserl o primeiro a englobar numa só teoria a imagem mental e a imagem física, assim proficuamente alargando o tema da imaginação;

2.1. dentro da imaginação propriamente dita, distinguir-se-ia, ainda, a imaginação como vivido particular da imagem enquanto modificação universal aplicável a todos os vividos;

2.2. no caso da imagem física terá de conferir-se algum relevo à consciência estética (que não coincide exatamente com o conceito de consciência de imagem).

\section{Imaginação, intencionalidade e intuição}

Brentano, um dos mestres de Husserl, opôs-se claramente à orientação da psicologia positivista que à época fazia furor, uma vez que colocou a tónica na especificidade do fator psíquico enquanto tal. Husserl acentuou do mestre o essencial: a relação intencional é sempre referente a um objeto, sendo esta a propriedade (intencional) dos fenómenos psíquicos. Daqui, a classe dos vividos intencionais englobar fenómenos tão díspares como a perceção, a imaginação, o juizo, o amor, o ódio, o desejo, etc., mas donde a sensação (Empfindung) é excluída, pelo motivo de ser o «simples material» que permite «construir» os atos - e neste ponto se afasta já o discípulo do mestre. Mais rigorosamente, «São [sempre] as intenções que especificam os atos. Se cada ato é diferente de todos os outros, é porque a sua intenção é diferente da dos outros atos». ${ }^{4}$ Desta feita se compreende a noção de objeto intencional. Este objeto (Gegenstand) é o que é visado nos vividos intencionais da consciência e não o que entra na consciência como se fosse, de facto, uma coisa. Toda interpretação da aperceção percetiva, de qualquer objeto real, do mundo portanto, sempre supõe um visar do mundo mas onde o mundo, ele mesmo, é o objeto intencional do ato, quer dizer, o objeto aparece mas não é vivido, já que se apresenta à consciência através dos seus conteúdos imanentes. Husserl empregará, assim, indiferentemente, os conceitos de apreensão, aperceção e interpretação. De resto, essas tradicionais distinções da filosofia husserliana, 
por exemplo, ato e conteúdo imanente, intenção e sensação, noese e noema, momentos reais (noéticos ou hiléticos) e momentos não-reais (noemáticos), etc., constituem, no fundo, a base conceptual de toda a futura reflexão dos filósofos que, de uma forma ou de outra, não puderam escapar à influência do pensador alemão.

Seguindo a tese sartreana de L'imagination - «a própria conceção da intencionalidade está destinada a renovar a noção de imagem» ${ }^{5}$ - explicita-se claramente a revolução husserliana no campo da imagem: a distinção entre imaginação e perceção não é de ordem de grau mas de essência (uma vez que a imagem não é uma cópia das nossas perceções, pelo contrário, ela possui uma intenção outra. Estudar o ato imaginante é analisar a apreensão imaginante, isto é, a unidade carácter do ato/conteúdo sensorial (que lhe corresponde). É evidente que toda imaginação se funda sobre a perceção, mas a imagem, por si própria, constitui-se mediante uma atitude específica da consciência, a qual confere a um objeto a seu carácter de imagem (o que, por sua vez, a faz diferir do modo puramente percetivo). Torna-se evidente que este discípulo de Brentano, e crítico de Hume, se afasta da Bildertheorie - aquela que «arruína a explicação intencional das relações entre a consciência e o mundo» ${ }^{6}$ renegando, de modo visível, o empirismo sensualista, que sempre advogou o «fora» (da consciência) das coisas e o seu representante (na consciência) enquanto imagem. Nas palavras da autora, «Husserl enuncia aqui um princípio muito importante: longe de ser uma fonte de erros, a imaginação é uma consciência tão válida como qualquer outra e que deve ser estudada na sua especificidade». ${ }^{7}$

Eis uma estranha teoria filosófica: a imaginação possui validade! Que tipo de validade se trata? Haverá, pois, que estudar a intencionalidade, só ela pode dilucidar a estrutura específica da consciência imaginante («imageante», no original francês). Por ora, sabemos que a imagem deriva de um objeto percecionado, mas o seu carácter de imagem é-lhe, tão-só, conferido não por esse objeto mas pela consciência.

E no $3 .^{\circ} \S$ do Capítulo I - uma introdução à análise da estrutura intencional da imaginação - Maria Manuela Saraiva apresenta ao leitor, aquele mais interessado na cientificidade do léxico husserliano, toda uma sistemática anotação e explicitação da significativa aparelhagem conceptual da teoria da imaginação, a saber, imaginação livre, consciência de imagem, imagens externas, representação imaginante, sujeito da imagem, objecto-imagem,

\footnotetext{
5 ISH, 55.

${ }^{6}$ ISH, 63.

${ }^{7}$ ISH, 68.
} 
(livre) fantasia, ficção, consciência estética e consciência de retrato. Adverte-se, inclusive, para não se confundir imagem e representação imaginante. No entanto, serão conceitos como intuição, presentificação e neutralização, que auxiliarão qualquer estudioso a compreender a verdadeira fenomenologia da consciência imaginante.

Já a partir do Capítulo II é revelada a tese da imaginação enquanto Erkennung durch Analogie, enquanto forma (intuitiva) de conhecimento, se bem que fundada sobre a intuição percetiva, uma vez que Husserl se mostrará suficientemente empirista para poder crer em algum tipo de ideias anteriores à perceção. ${ }^{8}$ Qualquer significação necessita de alguma intuição para se poder fundar originariamente, ou pela primeira vez. Contrariamente, o ato de significar manifesta-se num nível intermédio entre a perceção e o enunciado dessa perceção, Por exemplo, digo a alguém que vejo um melro a voar sem que essa pessoa realize, necessariamente, um ato percetivo ou imaginativo.

Já no seu artigo «O primado da perceção e a conceção da obra de arte em Husserl», Maria Manuela Saraiva referira o mesmo exemplo. A significação de uma expressão comporta uma verdade ideal idêntica a si mesma, remanescendo inalterável na multiplicidade dos atos em que essa expressão se enuncia. Portanto, a significação é o «elemento comum» concomitante à expressão assistida, ou não, por um ato intuitivo. Quando enuncio: 'um pássaro voa', trata-se de uma expressão independente das circunstâncias desse enunciado, da perceção, etc. ${ }^{9} \mathrm{O}$ velho esquema do uno e do múltiplo das Investigações Lógicas (a multiplicidade dos atos, sujeitos ou circunstâncias), que se relaciona, efetivamente, com uma significação única, qualifica ainda o tom da filosofia husserliana que se encontrará em Formale und Transzendentale Logik. ${ }^{10}$ É, precisamente, esta idealidade da significação que faz convergir tanto o «especialista de lógica» (cujo tema é a linguagem) como o «especialista de estética» (cujo tema é a obra de arte), como veremos mais à frente.

Maria Manuela Saraiva introduzirá o neologismo (por inspiração de uma tradução castelhana, dentro das várias consultadas) de intuitivização para traduzir Veranschaulichung, um estado intuitivo que existe em todo o preenchimento, a concordância entre a intenção e o ato que lhe confere plenitude. Haverá agora que inquirir: qual é então a espécie de preenchimento que pertence à imaginação? Parece que a imaginação assume um estatuto que normalmente se poderá considerar pouco expectável: o de um preenchimento

8 ISH, 85.

9 Cf. A Obra de Arte Literária (OAH), de Roman Ingarden; trad. Albin E. Beau, Maria da Conceição Puga e João F. Barrento, 2. ${ }^{a}$ ed. Lisboa: Fundação Calouste Gulbenkian, 1979, pp. 97 e ss.

10 Em 1929, Formale and transzendentale Logik: Versuch einer Kritik der logischen Vernunft. 
autêntico, ou seja, a identificação entre aquilo que é visado e aquilo que é intuicionado. «A nossa conclusão é a seguinte, escreve a professora, quando Husserl fala de preenchimentos ou intuitivizações autênticas, pensa indiferentemente na perceção e na imaginação». ${ }^{.1}$ Por exemplo, quando digo «tinteiro» ou «melro que voa» significo um vazio (significação vazia) que se pode preencher de modo autêntico quer por uma perceção, por uma recordação ${ }^{12}$ ou por imaginação livre, sendo que tais atos possuem as mesmas matérias.

Haveremos de admitir, qualquer dos modos, que o objetivo de dar a própria coisa que a perceção possui, não passa de uma pretensão, sabendo que, por essência, a perceção sensível (também) é limitada. Não obstante, é esta que funda, por exemplo, a consciência signitiva, a consciência do signo ou de sinal. Neste caso, falamos já de uma referência que, por natureza própria, não é preenchida. É verdade que uma expressão verbal, por força exprimirá uma semelhança entre o sinal e o designado (veja-se o exemplo do «melro»), mas nessa incompletude se fica. O que nos remete para outro problema.

$\mathrm{E}$ distinguiremos, por conseguinte, perceção transcendente (perceção mundana das coisas) e perceção imanente (reflexão sobre os dados da consciência) para se perceber, de seguida, que na primeira o objeto nunca é realmente dado como ele é de facto, dele apenas se vão captando esboços num contínuo, fragmentos, faces, perspetivas, segundo uma incontornável inadequação; por contrário, a segunda mantém-se adequada: uma vivência não se dá por meios de esboços. O que significa isto para o ato de imaginação? A imaginação preserva o seu intrínseco estatuto intuitivo de inferioridade por relação à intuição percetiva na qual se funda (retomaremos o assunto).

Por questões metodológicas e pedagógicas, impõe-se de momento mostrar duas conclusões:

a) a presentificação por representante físico (consciência de imagem) e a referência não preenchida às coisas (consciência signitiva) não terão sido completamente elucidadas por Husserl nas Investigações Lógicas e em Ideias I;

11 ISH, 98.

12 Sabe-se, no entanto que Husserl não distingue, com propriedade, imaginação e recordação. Ambos os atos são derivados e irrelevantes para o conhecimento imediato. Só na sua relação com a perceção originária eles teriam um valor cognitivo específico. $O$ que torna bastante irrelevante para Husserl o aspeto criador da livre imaginação, a fecundidade estética da imaginação criadora. A invenção não é contemplada, contrariamente àquilo que, de modo teórico, Husserl deixará supor (como bem refere Maria Manuela Saraiva na Conclusão de L'imagination selon Husserl). A imaginação husserliana, a livre imagem, ficaria, assim, «bloqueada» no carácter material de uma recordação neutralizada de uma mesma matéria. 
b) Husserl mostrou fundamentalmente a importância da intencionalidade signitiva e imaginante, descobrindo, assim, a faculdade imaginativa enquanto função integrante da nossa experiência do mundo, isto é, «Não imaginamos apenas quando, de olhos fechados, nos abandonamos ao sonho, nem mesmo quando olhamos um retrato ou percorremos uma sala de museu. Estamos sempre a imaginar, mesmo quando, de olhos bem abertos, julgamos apenas apercebermo-nos do que se encontra diante de nós.» - na verdade, e numa mera exemplificação: é impossível «olhar simultaneamente a parte da frente e as costas de uma cadeira». ${ }^{13}$

\section{Imaginação, presentificação e neutralização}

Nos $3 .^{\circ}$ e $4 .^{\circ}$ capítulos de $A$ Imaginação segundo Husserl deparamo-nos com a decisiva importância dos conceitos de presentificação e neutralização, como forma de explicitar as grandes novidades do pensamento husserliano. Desejando, desde já, antecipar ou resumir o fundamental, em nosso entender, dos temas supra assinalados, afigura-se-nos proveitoso referir que a partir da sua especificidade intencional, característica de outras vivências da consciência, a temática da imaginação tomou com Husserl um novo rumo adentro do universo filosófico.

A imaginação é uma modificação da perceção transcendente, é uma presentificação. Toda a espécie de imaginação possui uma forma característica de apreender os objetos: a presentificação (Vergegenwärtigung). Assim, e enquanto vivência particular, a imaginação é presentificação neutralizada do objeto de um ato percetivo anterior. Enquanto modificação universal aplica-se a todos os atos da consciência. Recuperando o sentido próprio de neutralização, ou seja, privar de validade, não decidir, pensar sem tomar partido, diremos que o fluxo egológico das vivências pode ser constantemente alterado pela neutralidade, quer dizer, pela modificação de neutralidade (Neutralitätsmodifikation) enquanto possibilidade constante relativa a todos os modos da consciência. A consciência de imagem (presentificação por representante físico), as disposições, os sentimentos, as paixões da alma por assim dizermos, todas as modalidades dóxicas de um modo geral são, igualmente, afetadas pela modificação de neutralidade.

Quer-nos parecer que a plurivocidade desta expressão, em Husserl, afeta a clareza, brevidade e o distinto modo da sua definição. Não obstante, como refere Fink, interpretemos essencialmente a modificação de neutralidade

13 ISH, 132. 
como «uma modificação específica da crença na experiência: uma crença sob o modo do como-se [als ob] ». ${ }^{14}$ Ela, enquanto constituição de aparência (como-se), é um modo primário de ser do ego puro e depende da liberdade deste último para existir segundo uma inautenticidade das suas produções constitutivas, se quisermos, segundo uma constituição neutra ou de aparência, de engano, ilusão - quando a consciência (neutra) retém o visado sob o modo do como-se neutro, ${ }^{15}$ do quasi. É errado, no entanto, identificar, de ânimo leve, imaginação e neutralização. Apreender um objeto sensivel enquanto imagem supõe também uma consciência imaginante (se bem que de um tipo outro). Com efeito, a presentificação (que pode ser ou não posicional) é o processo fundamental de toda a consciência imaginante. Mas no caso de esta ser neutra temos aberta a via para outra espécie de modificação imaginativa, a neutralização ou consciência estética - que, de resto, Husserl pouco explorou mas onde a nossa autora se aventurou.

Avancemos com uma ilustração nossa: numa exposição de arte perceciono determinada gravura em cobre que me prende a atenção: a gravura de um cavaleiro num torneio medieval e o que, por exemplo, me faz interrogar de que época seria. Assim, a gravura é presentificada, num ato dóxico ou posicional de interrogação, à minha consciência. Nesta, aparece por abstração uma figura-imagem, um objeto intencional que reproduz ou que se parece com a figura-coisa - consciência de imagem por representação física. Ora, a certa altura, depois de me aproximar e de a observar com um pouco mais de atenção, a minha imaginação, a liberdade radical do meu ego, solicita o meu pensamento (juízos) para um outro modo de ser da minha consciência e, por gozo estético, esqueço esse mundo das realidades onde me encontro (na sala de um Museu de Arte Antiga). Apesar de o meu modo de apreensão ser o mesmo (pois continuo a ver o cavaleiro e tudo o que envolve a sua imponente figura), já o não é a minha relação psicológica com o modo de existência dessa gravura enquanto imagem mental ou objeto intencional na minha mente: limito-me a um mais restrito entendimento ou compreensão do sentido que a gravura me comunica. Quer dizer, já neutralizei (ou deixei de tomar posição perante) esse ato primeiro de perceção, e fiz, talvez sem o querer, com que ele perdesse a força do real, tornou-se irreal. Por conseguinte, pela neutrali-

14 «La modification de neutralité désigne alors une modification spécifique de la croyance en léxpérience: une croyance sur le mode du comme-si». E. Fink, De la phénoménologie, traduit de l'allemand par Didier Franck, avec un avant-propos de E. Husserl. Paris: Ed. de Minuit, Arguments, 1974, p. 84.

15 Como-se neutro neste caso, pois também se considera um como-se conforme à modificação de representação ( $c f$. Fink, ob. cit., p. 84). Contudo, e de um modo geral, o como-se é «o único carácter descritivo fundamental de todas as representações.» (Fink, ob. cit., p. 70). 
zação, a gravura como volume, em cobre, etc., por assim dizer desapareceu, para ser substituída pela obra de arte. A minha consciência está, de momento, preenchida com uma outra modalidade dóxica de relação à existência desse objeto intencional, ou seja, o ato de crença foi anulado e surgiu uma simples presentificação imaginante sem carácter posicional. Eu sei que o cavaleiro não está ali mas imagino-o, sinto-o, etc., como-se estivesse. No entanto, se essa presentificação é novamente neutralizada (por exemplo, se não penso sequer o cavaleiro como existente ou não existente) então, experiencio um outro grau fenomenológico de neutralização. Basta-me a obra de arte como simples aparência, recortada da esfera ontológica, sem relação alguma à realidade que ela representa. Seria esta, no dizer de Maria Manuela Saraiva, a atitude puramente estética que, não se reduzindo a um ou outro grau de imaginação, abriria as portas à irrealidade peculiar do universo artístico. A visão transfigurada, o resultado da (dupla) neutralização desse «carácter tético da existência que acompanha sempre a perceção normal», ${ }^{16}$ eis o que torna possível a atitude puramente estética. Desta maneira forjaria a obra de arte um apelo não à imaginação mas a uma espécie nova de perceção, a perceção artística - eis o que a autora conseguiu indiretamente retirar do primeiro volume das Ideias de Husserl.

$\mathrm{E}$, de momento, parece-nos forçoso concluir o seguinte: o ato de imaginação é sempre presentificativo mas nem sempre é neutralizante. Quando se neutraliza o carácter da crença (Glaube) (esse «carácter fundamental da intencionalidade»), surge a imaginação livre - tratando-se ainda da mesma matéria intencional. Compreende-se portanto a familiaridade existente entre imaginação livre (fantasia) e consciência estética. A neutralização imaginante faz com que o sujeito aceda à dinâmica da função estética, ao jogo ou movimento constante entre o real e o irreal, entre o que existe perante a minha perceção e o que eu imagino mediante a minha liberdade de fantasiar - que em última instância é sempre e de algum modo referida à primeira. $O$ mesmo acontece com a consciência simbólica. De facto, para o autor das Logische Untersuchungen tanto a obra romanesca, a literatura de ficção, como as artes plásticas de um modo geral, são unificadas por este tipo de neutralização.

Diremos que ao universo noético auto-presentativo do artista, do escritor, do poeta, corresponde a presentificação neutralizada. Trata-se da imaginação livre e da consciência estética e não de presentificações posicionais, como sejam a recordação ou a consciência de retrato (uma forma de consciência de

${ }^{16}$ Cf. Maria Manuela Saraiva, "O primado da perceção e a conceção da obra de arte Husserl”, Coimbra: Imprensa de Coimbra, 1965 (Separata de Perspetivas da Fenomenologia de Husserl, 73-106), p. 79. 
imagem: consciência de imagem por representação fisica). No entanto, existe um (difícil) ponto essencial comum à recordação e à livre imagem: precisamente a aparição (ou imagem) intuitiva imaginante (Phantasieerscheinung). De outro modo, tanto à imagem-memorial (posicional) da recordação como à simples-imagem (não-posicional) da imaginação, corresponde uma presentificação, a saber, no caso da recordação, uma presentificação posicional; no caso do ato de imaginação, a contrapartida dessa modalidade dóxica ou uma presentificação neutralizada. Por conseguinte, e à semelhança da consciência imaginativa, enquanto imaginação livre e desperta pela neutralização da sua recordação-base, mostra-se também que a recordação possui algo de fenómeno imaginário.

Outra conclusão: para compreender a imaginação há que articular presentificação e neutralização. Não se afigura suficiente interpretá-las como (apenas) dois processos justapostos. Para a compreender, torna-se necessário analisá-las enquanto unidade conjunta. A imaginação é, portanto, uma modificação de neutralidade ou significação universal suscetível de se aplicar a todas as vivências ou atos da consciência. ${ }^{17} \mathrm{~A}$ imaginação tem que ser analisada enquanto modificação representativa (presentificação) e enquanto modificação qualitativa (neutralização ou modificação de neutralidade). Nas palavras de Fink: «A imaginação é, antes de mais, uma modificação uni-

17 Certamente que semelhante temática implicaria uma reflexão mais cuidada sobre a doutrina fenomenológica da redução transcendental. Seríamos, com efeito, levados a pensar que o campo da redução transcendental teria, ela mesma, uma zona de aplicação tão vasta como a própria imaginação. Não faremos semelhante investigação, pois transcende o nosso propósito momentâneo. Mas acerca do tema, apenas uma nota: a modificação de neutralidade admite um papel fundamental na fenomenologia científica através da epoché universal. A saber, para que se possa descrever, como é intenção da fenomenologia, a relação noético-noemática da pura consciência com o mundo-fenómeno (o seu correlato noemático), a fenomenologia tem de se limitar a receber o dado, ou seja, tem de se assumir como consciência neutra. É esta a perspetiva que nos interessa. Não obstante, é necessário mostrar o carácter platonizante da teoria das essências deste filósofo. Um estudo interessante, e para nós suficientemente representativo desta questão, é o curso dado por Edmund Husserl no semestre de verão de 1925 na Universidade de Freiburg, acerca de psicologia fenomenológica ou intencional (obra editada postumamente, por Walter Biemel, em 1962 - Phänomenologische Psychologie - e retrovertida para a língua inglesa por John Scanlon em 1977, na editora oficial das obras de Husserl). A dada altura, o filósofo apresenta-nos a variação eidética como método de diferenciação do binómio factual (Faktisch) / fantasia (Phantasie), concluindo acerca da permanência e invariabilidade da ideia (eidos). Por exemplo, oiço, de facto, um tom ou opto por fantasiá-lo. Mas $o$ tom, "tomado universalmente», a eidos, mantém-se através da mente, nessas «variações opcionais» e, no caso vertente, «comummente necessárias»: «Z. B. verfahren wir so im Ausgang von einem Ton, mögen wir ihn nun wirklich hören oder als Ton "in der Phantasie vorschweben" haben, so gewinnen wir daran das im Wandel "beliebiger" Varienten erfasste Eidos Ton als das hier notwendig Gemeinsame» (Phänomenologische Psychologie. Vorlesungen Sommersemester 1925. Herausgegeben von W. Biemel (Hua IX), zweite Auflag. Den Hague: Martinus Nijhoff, 1968, § 9a, p. 73). 
versal de toda a vida da experiência». ${ }^{18} \mathrm{O}$ mesmo é afirmar: a imaginação é sempre fundada.

Voltando agora à nossa autora, e em tom de corolário: «A ideia que este texto traduz é clara: os conteúdos representantes, quer pertençam à perceção, quer pertençam à imaginação, são como reflexos cuja característica profunda é a semelhança com aquilo de que são reflexos. São Abschattungen, sombras, figurações imanentes dos objetos intencionais dos atos. Não são o objeto, mas representam-no, substituem-no, por assim dizer, na imanência real da consciência e é por seu intermédio que a consciência se reporta a algo diferente de si própria». ${ }^{19}$

Em abono da verdade, e de acordo com Husserl, nas suas Investigações Lógicas ${ }^{20}$ a perceção e a imaginação coexistem de modo a que à primeira corresponde, sempre, uma imaginação possível. Por outro lado, a priori, qualquer ato de perceção é ele próprio fonte de presentificações. Por conseguinte, todos os atos presentificantes, inclusive a presentificação imaginária, são modificações de uma experiência originária (as perceções de coisas portanto). Por sua vez, a própria imaginação livre, a livre fantasia por assim dizer, é, por sua vez, circunscrita ao carácter da presentificação. Esta assume-se como a negação do ato doador da apresentação originária sendo que nenhuma representação poderá nela encontrar a sua fonte. ${ }^{21}$ Por isso, presentificar é tornar presente, repetindo uma presença originária. $\mathrm{E}$ assim se evidencia, de igual modo, a impossibilidade da presentificação categorial: «não há consciência presentificante senão daquilo que é isolado no tempo», o que exclui, logicamente, qualquer presentificação das objetidades ideais (como a recordação, por exemplo) ou as representações universais por analogia (uma curva desenhada no papel, ou simplesmente imaginada sem ser intuitivamente dada). ${ }^{22}$

Mas no que respeita, de modo mais específico, à imaginação, teremos de concluir que ela se constitui, tão-só, como uma neutralização implantada numa presentificação. Tanto a presentificação como a neutralização são caracteres noemáticos que se fundem na completude do noema, dizendo respeito, respetivamente, ao modo da apreensão e ao modo da crença.

Todo o tipo de imaginação é presentificação, ou seja, a presentificação que se opõe à (a)presentação (doação originária da perceção) manifesta-se

${ }^{18}$ Fink, ob. cit., p. 36.

19 ISH, 144-145.

$20 \mathrm{ISH}, 161$.

21 ISH, 167.

22 ISH, 175. O conceito de categorial refere-se apenas ao objeto supra-sensivel ou ideal, quer dizer inapreensivel pelos sentidos. 
enquanto modificação da perceção transcendente. Mais, em todo o tipo de presentificação transitam dois modos de crença, a posição e a neutralização.

Em esquema teríamos o seguinte:

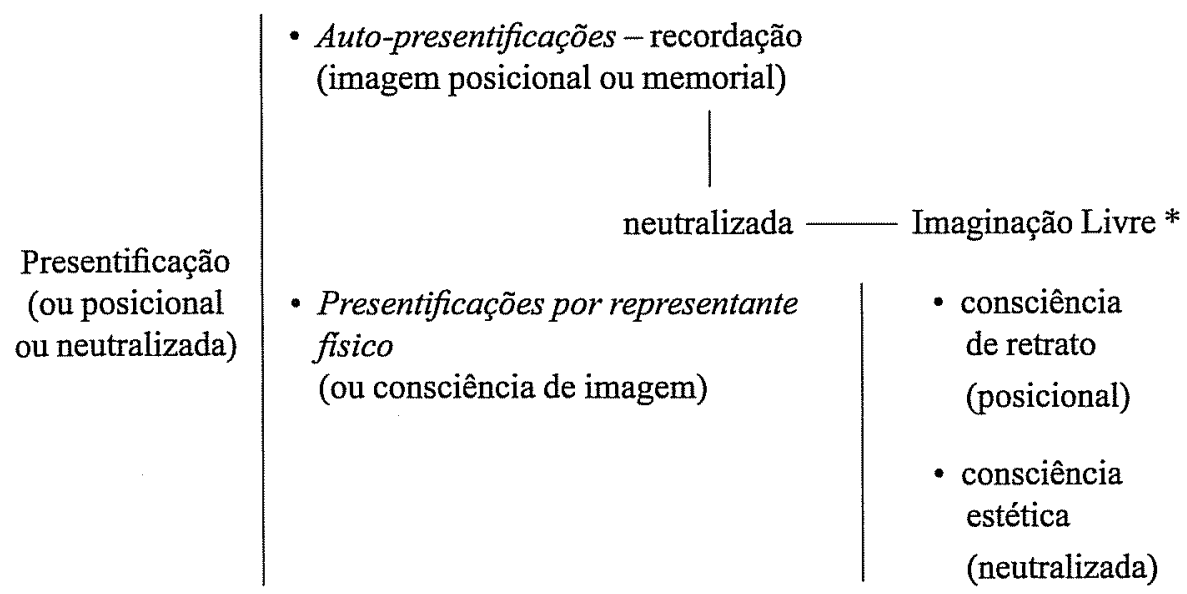

* como vivência particular (presentificação neutralizada do objeto percecionado) ou como modificação universal (aplicável a todos as vivências/atos)

Sabemos, por ora, e de acordo com Ideias $I$, que «a imaginação é ela própria, de facto, uma modificação de neutralidade». ${ }^{23}$ Evidentemente que se deu um salto qualitativo entre as Investigações Lógicas e esta última obra, o que definirá, numa primeira fase, o pensamento subsequente do filósofo. Melhor, em Ideias I, a noção de modificação de neutralidade estende-se para se identificar com a própria redução transcendental, para, enfim, se assumir como método que franqueia as portas à fenomenologia científica, à figuração «simplesmente como pensamento», na consciência, do correlato noemático que é o mundo-fenómeno.

\section{Imaginação e redução. A abertura do universo artístico}

Retomemos, agora, uma importante nota: a redução transcendental - essa «forma privilegiada da consciência neutra» ${ }^{24}$ - possibilitará, à semelhança da imaginação, neutralizar o ser, ambas se aplicando a uma vastíssima zona de fenómenos. Problema: como distingui-las então? 
Recapitulando: enquanto modificação representativa a imaginação é presentificação e enquanto modificação qualitativa ela é neutralização. Seguidamente, é imperioso diferenciar entre atos posicionais (enquanto atos de crença) - v.g. perceção, recordação, expectativa, juízo, etc. - e atos imaginantes (as suas contrapartidas neutras). Mas a especificidade aumenta: existem atos não-posicionais e que não são imaginantes e atos imaginantes e que são posicionais.

Maria Manuela Saraiva descobre, neste ponto, como em outros aliás, a ambiguidade do pensamento de Husserl, admitindo, inclusive, que o pensador alemão se «exprime mal» e não chega a articular «corretamente» os dois processos base da consciência imaginante. Mas a professora ensina: «O que ele quer dizer, ou antes, aquilo que subentende, é, no fundo, muito simples: para que um objeto sensivel nos surja como imaginado, é necessário que tenha atuado uma apreensão imaginante. Por este facto, a apreensão de um objeto sensível como «imagem» é já uma consciência imaginativa. Por outras palavras, o processo de presentificação é o processo-base que intervém necessariamente em qualquer forma de consciência imaginante. Mas essa presentificação pode ser posicional ou neutra». ${ }^{25}$ Ora, se for neutra, foi porque interveio um tipo outro de modificação imaginante, a neutralização estética, o que implicará interpretar-se o ato de imaginação como presentificação mas nem sempre como neutralização. Ao tratar-se desta última teremos, então, de falar, num «sentido muito lato», de consciência estética.

Noutra perspetiva, a inatualidade da imaginação não lhe permite a referência, num agora atual, entre o passado e o presente. Deste modo se percebe que «aquilo que o tempo objetivo é para os objetos que pertencem ao mundo real, é-o o tempo imanente da consciência relativamente aos atos de imaginaçãon. ${ }^{26}$

A velha fórmula kantiana de que o «tempo é a forma da sensibilidade» foi verificada por Husserl. O carácter que precede todos os outros é, com efeito, o tempo, o que permite que qualquer objeto se dê numa unidade intuitiva portanto. Está bom de ver que, nos casos específicos dos atos da imaginação, se tratam de situações no tempo imanente da consciência: os seus objetos são ficções e não podem existir em algum tempo objetivo. Por isso, ao mundo e ao tempo da perceção correspondem o mundo e o tempo como se da imaginação; a cada mundo imaginário diz respeito uma unidade de tempo de uma experiência possível. Todas as ficções artísticas possuem este carácter. 
E no caso das ficções estéticas, um tema caro à autora como sabemos, deparamo-nos com a neutralização imaginante. Segundo o famoso exemplo, ao observarmos a gravura de Dürer, $O$ Cavaleiro, a Morte e o Diabo, na perspetiva de Husserl, identificam-se (inexplicavelmente, segundo Maria Manuela Saraiva) imaginação livre e consciência de imagem. Em rigor, quando o fenomenólogo trabalha com o método das variações livres (imaginando portanto o que realmente não se percecionou), isolando, desse modo, as essências, ele encontra-se em situação de neutralização geral do ser, mas não numa modificação imaginante dessas mesmas vivências (o que implicaria já a mediação da recordação).

Segue-se que a neutralização pela imaginação é radicalmente descoincidente da atitude que o fenomenólogo ensaia? E, para repetir a questão de G. Van Riet, «Que é esse sujeito (ou quase-sujeito) planando sobre as operações exercidas, esse sujeito desincarnado que descreve soberanamente, que vê, refiete, descreve o que vê e confere a consciência realı? ${ }^{27}$ É com tal questão, a da epoché no fundo, que a autora encerra esta fabulosa tese sobre a imaginação em Husserl ou, o que é o mesmo, sobre a essência do pensamento de Husserl.

Para Maria Manuela Saraiva, o que Husserl afirma, sem dúvida alguma, é que a neutralização quase se identifica com a epoché, reencontrando-se, de modo incontornável, o núcleo central desta filosofia. Para o reanalisar são-nos propostas algumas reflexões. Em primeiro lugar, a consideração sobre a relevância do «caminho cartesiano». Sabe-se que Husserl se opôs à «ilusão» de Descartes, afirmando a «certeza» da consciência enquanto fechada sobre si mesma e (autoimune) à dúvida, relegando desta feita para plano menor o cenário da «destruição do mundo» pelo pensamento. Eis-nos agora, pedagogicamente, na descoberta da consciência enquanto cogitatum qua cogitatum.

Diríamos nós que a consciência psicológica (zona do ser) é, por isso, posta entre parêntesis ( $\dot{\pi} \pi \circ \chi \eta ́)$, para se poder dar atenção à vida da consciência por si, onde a contingência dos entes, a dúvida e a mutabilidade do ser, escapa à (descoberta da) essência da consciência. Descartes foi o grande pedagogo orientador e Husserl ultrapassou o mestre - esta via cartesiana terá sido sistematicamente desenvolvida por Husserl no primeiro volume das Ideen e, pelo menos, até à edição da Krisis em 1936. No entanto, a epoché mais não faz que pôr fora de circuito uma equívoca ideia acerca da consciência e da forma como esta julgava apreender o objeto transcendente. Cria um vazio para dar início a um novo discurso. Constitui-se, com efeito, como atitude teórica que é, mais como uma re-condução do homem a si mesmo do que um simples método de 
pôr entre parêntesis. ${ }^{28}$ Descobre-se o mundo como o pensado, como o que simplesmente aparece $a ̀$ e se esgota $n a$ (pura) consciência do sujeito. O ser que transcende o sujeito, o mundo, só é como cogitatum qua cogitatum. No âmago da imanência pura o pensado surge tão-só como o correlato de um ato de pensamento (cogito) ou, de outro modo, o noema apenas se compreende como correlato da noese. Toda a espécie de filosofia que pretenda desligar os momentos ideais ou intencionais (caracteres noemáticos) dos momentos reais ou hiléticos (caracteres noéticos) do objeto, torna-se artificial. A qualidade do ato intencional (ou o modo em que o objeto é visado, de um modo geral, pela perceção, recordação ou imaginação), é inseparável da matéria do ato intencional (ou o modo do próprio objeto visado enquanto que percecionado, recordado ou imaginado) - o que Heidegger conceptualizará como $\mathrm{Als}$ Struktur (a estrutura enquanto que): o objeto apenas pode ser visado enquanto tal (ou tal). Por exemplo, afigura-se absurdo querer recordar algo (qualidade) independentemente desse algo ter sido de facto vivido (matéria). Obviamente que não me é permitido recordar ou percecionar o vacuum ou o plenum do universo; a existência do(s) deus(es); a morte do meu ser. Por paráfrase de Kant, digamos que a consciência encontra os seus limites à custa da reflexão sobre (in)evitáveis paralogismos e outros raciocínios dialéticos que ela mesma produz. Não obstante, é-me permitido imaginá-los! Neste caso, por meio da livre fantasia ou simples imaginação, no sentido estrito dos termos. Qualquer dos modos, só por referência a um mundo já vivido é possível ao ego imaginar o que quer que seja. É pois pela via da redução fenomenológica, com os seus diversos momentos, que se evita por um lado a ambiguidade judicativa da relação eu/mundo e, por outro, se ganha o sentido noemático pertencente a cada vivência. Por exemplo, na recordação, ou na imaginação, depois de renovadas pela redução, apenas se detém o recordado ou o imaginado como tal. Não deve entender-se, no entanto, a redução fenomenológica enquanto uma subtração ou privação de algo que existe de facto - o que, de resto, não faria qualquer sentido - mas como indecisão, suspensão do juizo, ou melhor, neutralização. A fenomenologia, a limite, mais não é que a simples explicitação de uma situação no mundo. A reflexão sobre o próprio fenómeno pressupõe já o fenómeno, este não tem interior nem exterior. No fundo, assim com a obra de arte. Escreve a professora, na sua conferência de 1964: «Parece-nos

28 Ou como refere E. Fink (De la phénoménologie, p. 154): «On peut dire en manière de thèse: la réduction phénoménologique n'est pas primairement une méthode de simple «mise hors circuit», mais de re-condution (Zuriickleitung). Elle conduit le sujet philosophant, dans la prise de conscience de soi la plus radicale, à travers lui-même, vers la vie de croyance transcendantal (vie recouverte par son auto-perception en tant qu'homme), dont le monde 'est' le corrélat de validité.» $\mathrm{E}$ mais à frente: «[...] en un mot l'epoché phénoménologique n'est rien moins qu'une action intellectuelle sans conséquence, 'purement' théorique» (p. 180). 
portanto que as realidades presentificadas irrealmente coincidem exatamente com as manchas de cor ou os traços a carvão que lhe servem por assim dizer, de corpo irreal. A obra de arte, perdida como realidade mundana, faria apelo, neste caso, não à imaginação presentificante, mas a uma espécie nova de perceção, a perceção artística». ${ }^{29}$

Sucintamente: partindo da análise de uma «primeira época» de textos originais de Husserl, fase que culmina com a edição do primeiro volume das Ideen (1913), descobre a autora uma «ambiguidade fundamental» do pensamento husserliano sobre tal matéria (e que canoniza o ideal platónico de mimesis da arte realista já em declínio nessa altura): identificação da atitude do artista a uma simples presentificação posicional. No entanto, englobando a fase compreendida entre Ideen II e Formale und Transzendentale Logik (no fim da vida do filósofo), conclui, por outro lado, o «abandono» da noção de presentificação e o apelo à modificação de neutralidade para interpretar o que o próprio Husserl (já) chamava, em Ideen I, o «estético puro». ${ }^{30}$ Não compete discutir aqui o valor desta ou daquela espécie de arte, daquela outra corrente, mais abstrata ou não, independentemente dos seus valores sócio-políticos, etc. Aceitemos o pressuposto de que a arte vale por si, mostra-se por si mesma, enquanto objeto intramundano: «A obra de arte é manifestação, epifania. Só distanciando-nos do mundo em que faz irrupção, mas de que não tira a sua origem, a podemos entender na sua essência própria».. ${ }^{31}$

\section{Conclusão}

Retenhamos o seguinte: o fenómeno não está para além do seu aparecer, daí que nos ofereça o aparecer e o ser simultaneamente, ou seja, o fenómeno esgota-se totalmente no seu aparecer, numa evidência apriorística portanto.

Mas a realidade natural transcende o seu mero aparecer a uma consciência. Não se fica pelo dado da simples presença-mesma (Selbstanwesenheit), em carne-e-osso. Nela são ao mesmo tempo co-dados, ao ego transcendental, ao ego referido a um objeto, todos os aspetos ou partes do fenómeno. Por isso todo o objeto é mais visado do que dado. Eu viso, simultaneamente, como um todo, o horizonte, a planície, a montanha, a árvore, esta pedra, etc., na sua totalidade imediata, mas apenas um destes entes preenche, realmente, a minha intenção significativa, apenas um se dá, no momento, numa singular síntese de

29 OAH, 85.

30 OAH, 104, passim.

$31 \mathrm{OAH}, 106$. Temos para nós que o uso deste conceito de epipháneia, «ato de se mostrar», careceria de uma melhor explicitação por parte da autora. 
preenchimento da minha atenção. Talvez seja por aqui que a fenomenologia tanto se aproxima da arte...

E a intenção de Maria Manuela Saraiva, sobressai clara, inequívoca, (também) no fim da obra, algo que para a fenomenologia científica de Husserl, supostamente, não terá interessado: «A atitude do filósofo aproxima-se da atitude artística, pelo facto de ambas ultrapassarem as limitações da pressuposição do ser objetivo e apenas considerarem a simples aparência» - aproximando-se assim das interpretações propostas por Kaufmann..$^{32} \mathrm{~A}$ arte exige, supostamente, «o esforço para alcançar a verdade da experiência primeira», destruindo a barreira das convenções, o que, consequentemente, nos remete para a constituição (humana) do mundo espiritual, para a Umwelt. ${ }^{33}$ O colocar entre parêntesis, a redução que logrará delimitar a noção de natureza, incidirá então sobre noções como útil, belo, confortável, convincente, etc. Notemos que estamos a falar de uma natureza enquanto «esfera das simples coisas» e, de acordo com Husserl, «Nesta atitude não existem casas, mesas, ruas nem obras de arte: entramos no reino da pura materialidade espácio-temporal». ${ }^{34}$ Mas, em contrapartida, enquanto pessoas que somos, colocadas em situações determinadas, sociais, familiares, etc. (o que mais tarde o filósofo chamará Lebenswelt), enfim, a nossa vida quotidiana, e mais uma vez em linguagem husserliana: não o «mundo em si» mas o «mundo para mim», ${ }_{, 3}^{35}$ tudo isso, apenas se entende quando «abrimos os parêntesis fechados».

$E$ É, pois, no segundo volume das Ideias que Husserl sugere o ambiente propício «às manifestações artísticas. «Em Ideen II, escreve Maria Manuela Saraiva, há todo um horizonte, um universo humanizado e atravessado por significações culturais em que o quadro como quadro ocupa imediatamente o lugar que lhe é devido, quase poderíamos dizer o seu "lugar natural", se não tomarmos esta expressão em sentido próprio»». ${ }^{36}$ Desta feita se compreende, de momento mais facilmente, a passagem da natureza real (todos os objetos do mundo que caem sob a alçada do nosso quotidiano) para a irrealidade fisica (physisch Unwirkliches) desprovida de existência (as obras literárias e as obras de arte).

32 ISH, 260.

33 Ver, especialmente, a última parte de Ideen II.

${ }^{34}$ Cf. OAH, 87.

$35 \mathrm{OAH}, 89$.

36 Ibid. 


\section{Parte II \\ A «obra de arte» em Ingarden-leitor-de-Husserl}

\section{Introdução}

A verdadeira fenomenologia nasceu em 1913, aquando da vinda a lume de Ideen $I$, o primeiro volume de Ideias para uma Fenomenologia Pura e Filosofia Fenomenológica, na revista editada por Edmund Husserl, Jahrbuch für Phänomenologie und phänomenologischen Forschung, com a colaboração de outros famosos autores da escola fenomenológica, como Pfänder, Geiger, Reinach e Scheler, por exemplo. Verdadeira, dissemos, porque aí aparece o esboço primeiro da não menos famosa teoria da redução transcendental - resumidamente: a autodescoberta da consciência pura enquanto poder de constituição de todo o sentido, pelo qual capta o mundo, e de qualquer modalidade intencional dessa captação - num exemplo prático: interessa à fenomenologia não a própria mesa enquanto objeto exterior mas o sentido mediante o qual ela se manifesta à consciência do sujeito. Deste modo terá o filósofo de Göttingen ultrapassado, finalmente(!), o imperialismo da psicologia, imperialismo esse que terá pretendido (solidamente) fundar a própria lógica para, segundo este escopo último, intentar uma pontual solução para a crise das ciências nas décadas finais do século XIX e primeiras do século seguinte, que supostamente tinha reduzido, em conjunto com a história (leia-se, historicismo) todas as outras ciências (por exemplo a estética, a ética inclusive) a meras colónias do seu vastíssimo domínio. Enfim, trata-se da pertinente questão do psicologismo epistemológico (desde Hume) contra o qual Sartre também se insurgiu no seu famoso artigo de 1947, «Une idée fondamentale de la phénoménologie de Husserl, l'intentionnalité» (em Situations I). Para mais, quando Husserl escreve o primeiro volume das célebres Investigações Lógicas - Prolegómenos à Lógica Pura, em $1900^{37}$ - desejou explicitamente esclarecer que os conceitos lógicos não podem ser entendidos como meros produtos de operações psíquicas ou conteúdos de consciência. Não seria, pois, permitido confundir facto e essência (como de igual modo se referirá em Ideias I). Quer queiramos, quer não, noções como redução transcendental e constituição, irão adquirir o seu pleno sentido apenas (mas não tardiamente, em nosso entender) na maturidade do pensamento husserliano.

37 Veja-se a excelente versão portuguesa de Diogo Ferrer, editada pelo Centro de Filosofia da Universidade de Lisboa, dentro do projeto "Phainomenon - Clássicos de Fenomenologia", direção de Pedro M. S. Alves, 2005. 
A incontornável obra deste pensador alemão, em cuja originalidade não se inscreveu algum ismo, como bem referiu J. N. Mohanty, ${ }^{38}$ terá criado, muito provavelmente sem o ter desejado, o medo do psicologismo no discípulo Roman Ingarden que, por sua vez, não logrou a exigência do radicalismo metodológico da ciência fenomenológica. Ironicamente, o mestre polaco quando chega a Göttingen, em 1910, encontra já um Husserl desprezando a fase pré-transcendental das Investigações Lógicas (obra que motivara a demanda ingardiana).

O psicologismo maximizado, o subjetivismo portanto, ameaçará, com efeito, o rigor da especulação ingardiana sobre a identidade da obra de arte, algo que circunscreverá tal reflexão à teorização de duas coisas:

a) um (mais seguro) estatuto ontológico da idealidade pura (o conceito);

b) um estrato significativo (significação) originador de múltiplas e abertas leituras, conquanto a estabilidade lhe é conferida pelo próprio conceito.

Pertinentemente, a propósito de se saber se poderá existir então lugar para a subjetividade do leitor crítico, escreve Maria Manuela Saraiva: «Não se julgue que esta precisão é um pormenor sem importância. É muito mais do que isso. Na verdade, cada leitor-crítico não pode ler uma obra a não ser a partir da situação que ele mesmo é - situação sempre ligada a uma possibilidade de opção -, situação e opção reveladas já, e antes de mais, no método que escolhe ou consente para se introduzir no universo a explorar».$^{39}$

Uma das razões pela qual este Prefácio de Maria Manuela Saraiva se reveste de alguma importância na produção fenomenológica nacional, apresentando-se por si mesmo como um texto fundamental do pensamento da autora, é, indubitavelmente, a preocupação de fazer prevalecer a pureza husserliana digamos assim, mediante a demonstração das consideráveis influências que Husserl fez florescer em vastos campos de investigação, principalmente, e no caso vertente, no domínio da Teoria da Linguagem. Por exemplo, fortes semelhanças, e não menos assinaláveis diferenças, foram pela autora sinalizadas entre este grande filósofo e o pai da linguística moderna, Saussure. ${ }^{40}$

38 Ver prefácio (P) de Maria Manuela Saraiva à edição portuguesa de A Obra de Arte Literária, de Roman Ingarden; trad. Albin E. Beau, Maria da Conceição Puga e João F. Barrento, 2. ${ }^{a}$ ed. Lisboa: Fundação Calouste Gulbenkian, 1979, p. XvI.

${ }^{39} \mathrm{P}, \mathrm{pp} . \mathrm{xxv}-\mathrm{xxv}$.

40 Saussure originou uma doutrina do significado muito para além de Husserl, se bem que este anteviu, de alguma forma, o que hoje se chama análise estrutural. Denota-se, contudo, uma pertinente aproximação reflexiva entre os conceitos de imagem acústica (não o som propriamente dito mas a sua «empreinte» ou representação psiquica, em Saussure) e de imagem 
E o mesmo para com a Teoria dos Estratos de Ingarden, para com as teses de Pfänder e para com o grande representante da teoria fenomenológica em estética, Hartmann. Julgamos que por si só, tal temática daria um estudo específico. Por contra, e de momento, o nosso interesse encontra-se satisfeito ao constatarmos, com a autora, que a conceptualização dos estratos e funções da linguagem (Ingarden), a teoria do signo linguístico (Saussure), e as teses sobre perceção e significação (exploradas por Greimas, ou por Ponty), apenas para escolher os exemplos maiores foram, todas elas pensadas, previstas no fundo, por Husserl ou, tão-só por ele exatamente afloradas. ${ }^{41}$ Por seu lado, Ingarden, em A Obra de Arte Literária, refere com propriedade algumas temáticas e problemas que os próprios Saussure, K. Bülher, Jakobson, Eco, Greimas, Barthes, etc., retomaram com maior sistematicidade.

É conhecida, no mundo filosófico, a discussão acerca da importância e pertinência temática com que certos autores se tornaram predecessores de determinadas teorias posteriores à sua morte, ou mesmo ainda no seu tempo. Também sabemos que algumas teses podem surgir quase concomitantemente em continentes geográficos separados (como por exemplo a importância da originalidade de Bachelard sobre algumas teses de Kuhn). E numa época filosófica instalada em plena crise epistemológica, donde nasceram tantos pensamentos originais a partir de 1900 , e nas décadas seguintes, nomeadamente ao nível da filosofia da linguagem, seria natural, melhor, quase necessário, a interconexão maximizada de temas nascentes da primeira grande e revolucionária fonte filosófico-cultural do século passado, Edmund Husserl.

\section{A originalidade ingardiana}

Dentro da singularidade do trabalho ingardiano, há que referir, prioritariamente, a reflexão sobre estratos e funções (da linguagem), dois dos conceitos-

mental - como na tradição de Hume a Spencer e que remete para a insólita expressão de Sartre «filosofia alimentan», ao referir a recusa do postulado da imanência - enquanto marca («empreinte») ou imagem psíquica, o que aponta, de novo, para a renovação imposta pelo pensamento husserliano. Outra tónica conferida à vasta produção de Husserl, é a sua fundamental antecipação da hodierna ideia de comunicação: a linguagem serve para comunicar (cf. $\mathrm{P}, \mathrm{p} . \mathrm{XLVI})$.

${ }^{41}$ No que diz respeito à perceção e significação oferece-nos a autora, num estilo rigoroso mas elegante, a clara explicitação de que, em Husserl, se encontram estudados dois tipos de perceção, a sensivel (leia-se, a tradicional sensação) e a intelectual (leia-se, categorial). Admite-se, neste aspeto, a escrita de Husserl como algo ambígua. $\mathrm{E}$ a propósito de ambiguidade, a autora advoga uma devida revalorização de Merleau-Ponty, por ter «desembaraçado a filosofia do dualismo simplista de Descartes) ( $c f$. P, p. XxxvuI), sob pena de tornar a filosofia um pouco... ambigua. O mesmo para a importância que Freud dedicou aos fenómenos da ambivalência, reiterando-se então a necessidade de destrinça entre «dualismos falsos» e «dualismos certos». 
chave da obra vertente de Ingarden. O professor de Cracóvia preocupou-se, nomeadamente, com a função expressiva (Ausdrucksfunktion) e a função apresentativa (Darstellungsfunktion de Bühler ou a «função denotativa» de Jakobson). Sobre a função expressiva, não se torna de somenos importância referir que esse conceito fora anteriormente isolado por Husserl nas Investigações Lógicas, ${ }^{42}$ encontrando-se já em Twardowski, no fim do século XIX, e citado aliás pelo mesmo Husserl.

Ao lermos este texto, denota-se, na verdade, uma ênfase conferida à (suposta) influência (direta e indireta) de Husserl sobre o seu discípulo. Para mais, relativamente a este último, a renovação do seu pensamento terá em grande medida estagnado nas Investigações Lógicas e pouco assimilando a constante evolução do mestre, nomeadamente a nova atitude filosófica de Ideias $I^{43}$

Uma das questões que mais aglutinaram os vários pensamentos de Ingarden foi a seguinte: qual o ser das objetidades que se manifestam na obra literária? Resposta: é o ser puramente intencional, isto é, ontologicamente dependente da consciência que o cria - desprezando desta feita a decisiva e integral diferença introduzida por Husserl entre ser real e ser ideal.

Roman Ingarden não se libertará, contudo, do psicologismo. Ele manteve-se na «ambiguidade da primeira fenomenologia» ${ }^{44}$ (a das Investigações Lógicas portanto), continuamente oscilando entre a descrição fenomenológica e a descrição psicológica. Não assumiu, de modo verdadeiramente consequente, a dualística relevância da redução transcendental e da constituição.

A análise fenomenológica propriamente dita aparece, timidamente, de quando em vez, em $A$ Obra de Arte Literária. Inclusive, aquilo a que Ingarden chama a sua teoria do Wortlaut ${ }^{45}$ (a palavra no seu aspeto fónico) é, no dizer de Maria Manuela Saraiva, no essencial, a teoria husserliana do Wortzeichen (signo verbal) - termos, aliás, a que Ingarden recorre mais para o final da obra, assinaladamente, nos $\S \S 62,64$ e 66 .

Dentro desta linha de repescagem de influências, encontramos ainda uma convergência com K. Bühler e R. Jakobson, nomeadamente no que diz respeito à terminologia, autores, enfim, igualmente influenciados por Husserl. De facto, os conceitos de atos de comunicação e funções de linguagem, podem ver-se primeiro em Bühler e depois em Jakobson. Tais ascendências acabam

\footnotetext{
42 Disso fala Ingarden no $\$ 13$.

43 P, pp. XIV-XV.

44 P, p. XXII.

${ }^{45}$ Cf. P, pp. $\mathrm{x}, \mathrm{xxxy}, \mathrm{xxx}$ II, $\mathrm{xxxvIII}$
} 
por se «amalgamar» com a originária, mais longínqua mas mais marcante, a «leitura e o ensino de Husserl».

Num capítulo que serve para mostrar a vivente e profunda relação entre o nível de significação e o nível do mundo apresentado (capítulo 6), Ingarden insiste, nas palavras da autora, em que «[...] o conteúdo de sentido das frases é elemento decisivo para a constituição das objetidades apresentadas; numa frase que enuncia algo a respeito de um objeto $X$, esse objeto é determinado pela significação de sujeito da frase; as objetidades apresentadas numa obra são-no graças às unidades de significação; as relações objetivas desempenham uma função essencial na constituição do «mundo» que um texto ou uma obra nos apresenta». ${ }^{46}$

Sabemos que uma das teses mais caras a Maria Manuela Saraiva é a da imaginação ou, em linguagem ingardiana, a função representativa (ou de representação), e que se preferiu chamar, simplesmente, função de reprodução imaginária (enfim, função de reprodução) - Abbildungsfunktion. Trata-se da função do «como se estivéssemos vendo» ( $3 .^{\circ}$ estrato ingardiano), a intencionalidade intuitiva. A passagem ao irreal, que a modificação de neutralidade permite, acolhe no seu domínio toda a obra de arte, assim como a literatura de ficção ou o próprio espetáculo teatral (que Ingarden também estudou).

Encontramo-nos, agora, no campo da literatura, da intuição imaginária, campo esse vedado a toda verdadeira intuição, a perceção sensivel. E é a partir deste último conceito que se joga a inusitada questão da transcendência na imanência (da obra de arte) - isto para se interpretar corretamente o intencional husserliano.$^{47}$ A perceção sensível, ou doação originária enquanto ato intuitivo por direito próprio, é a que nos oferece o ser, as coisas em «carne e osso» - se bem que o ser sempre é captado num fundo espácio-temporal segundo perfis ou esboços parcelares, fragmentários (Abschattungen, como sabemos já), sucessivamente encadeados e completados. Ora, Ingarden elegeu o conceito de Ansicht (aspeto) - a antiga designação do seu mestre - para desbravar o horizonte da obra de arte (enquanto narração, descrição, diálogo, etc.), o qual emerge pela imaginação do leitor, atualizando o vazio, aquilo que está disponivel.

\section{Conclusão}

Numa pontual inspiração literária a partir da leitura do texto de Ingarden, escreve a autora: «Vemos determinada rua de Paris ${ }^{48}$ acompanhamos deter-

\footnotetext{
46 P, p. XLIII.

47 P, p. XLLX.

$48 § 42$.
} 
minada personagem e com ela atravessamos corredores e descemos escadas. ${ }^{49}$ Frequentemente nos identificamos com as personagens que mais nos tocam... Instantes fugidios e transitórios como as Abschattungen do ato percetivo, enigma de plenitude e esvaziamento, onde tudo está sempre a recomeçar e prestes a morrer. Espaços privilegiados de um livro que se dilatam, abrem o tempo para repetições imaginárias de paisagens experimentadas num passado que, por momentos, se anima e volve quase-presente... Espaços elásticos, de dimensões incertas, que também podem concentrar-se num ponto só, na intensidade de uma quase-presença resumida». ${ }^{50}$

Tal (terceiro) estrato da imaginação, os horizontes abertos pela liberdade imaginativa, é com o que Ingarden nos presenteia, pela atitude intuitiva esteticamente valorizadora da obra de arte literária. A obra é em si mesma autónoma enquanto apresentação de um mundo imanente na transcendência que perpetuamente se infunde no leitor, que perduravelmente se insinua na intencionalidade da consciência do intérprete.

Mas afinal, haverá, ou não, que se equacionar a hipótese de ser, justamente, este estrato preconizado por Ingarden que poderá, eventualmente, ameaçar a própria estrutura imanente da obra de arte?! Em boa verdade, não subsistirá, aqui, um «açambarcamento do estético» pela função da reprodução imaginativa? Porém, a Maria Manuela Saraiva não lhe aparece uma «contradição» mas uma «tensão», uma vez que a modificação de neutralidade continuamente exerce um peso e funciona como «travão» entre a imanência e a intuição, a saber, a realidade é uma quase-realidade que nunca fará viver, em concreto, a verdade da realidade vivida em presença de coisas.

\section{Nota final}

Dissemos: o tema da imaginação propriamente criativa, o caso das ficções, foi bastante mal elucidado por Husserl. Aliás, raramente o assunto foi convenientemente desenvolvido pelo grande filósofo.

Ora, em boa verdade, o que foi normalmente considerado por Husserl foi, tão-só, a imaginação ou imaginação livre, algo bastante arrebatado, por assim dizermos, pela recordação e, finalmente, dependente das sínteses passivas da perceção. Portanto, a imaginação criativa, a ficção, e a imaginação reprodutiva, a imaginação por si ou livre fantasia, não foram alvo de delimitações precisas na obra de Husserl, sendo a imaginação considerada uma síntese pas- 
siva formada a partir de dados sensoriais - o que se comprova pela referência expressa a este último assunto em alguns textos do mestre alemão. ${ }^{51}$

Independentemente de o emérito professor (continuar a) não se exprimir de uma «maneira clara e acessível» (no que diz respeito a estas matérias da estética, entenda-se) abrindo mais caminhos do que aqueles que conseguiu explorar, Maria Manuela Saraiva não o identifica, por exemplo, com Platão - e, podia fazê-lo de facto, como outros autores o terão feito - no que diz respeito à recorrente questão filosófica das significações puras, arquétipos que «incarnariam nas suas reproduções concretas».

Para abreviar: aquilo que era chamado o «estético puro» em Ideen $I$, é a «estética» a partir de Ideen II.

Mas então, da sua aparelhagem conceptual, o que se mantém até aqui? Resposta: a Neutralitätsmodifikation, ou seja, o que faz a ponte entre essas duas obras. Alguma novidade? Sim, o abandono da presentificação. E é isto, em rigor, que acelera a compreensão do universo artístico. Findas as ambiguidades, surge uma nova pista na fenomenologia husserliana. A obra de arte encontra-se, finalmente, no (tão almejado) estatuto de portadora de um sentido. Um sentido ideal, uma vez que o universo da obra de arte se basta a si mesma - «na obra de arte o espírito se faz verbo, forma, cor e som». ${ }^{52}$ Eis então um grande momento: o momento da libertação do primado da perceção, uma vez que a descrição fenomenológica do universo estético se autonomizou. Eis o progresso na evolução de Husserl!

\section{ABSTRACT}

Maria Manuela Saraiva was one of the rare authors that, in the Portuguese philosophical panorama, was devoted to the study of Husserl, namely in what she concerned the statute of the imagination versus aesthetic conscience or artistic universe. Starting with the analysis of their texts on Husserl and Ingarden, we will end considering the eventual aesthetic innovations in Husserl's work, that is to say from the Logical Investigations to the Formal and Transcendental Logic, going trough the phases imposed between the first and the second volumes of the Ideas. Surpassing the ambiguity of the husserlian language, and given the absence of an aesthetic thought of the master of Göttingen, we will see now the work of art can break out, pure, in itself, beyond the primacy of the perception and by the modification of neutrality. 